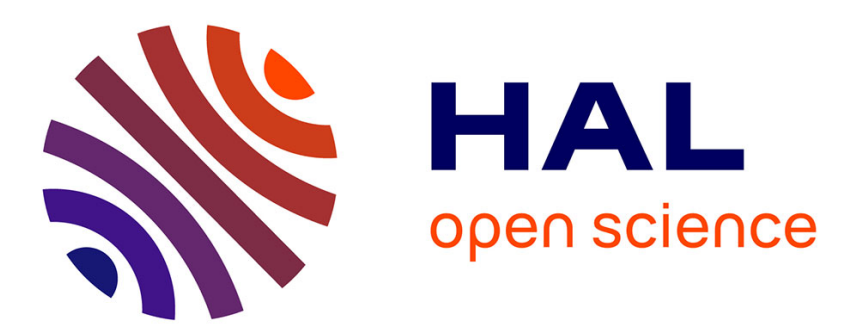

\title{
Interaction and interactives: collaboration and participation with computer-based exhibits
}

Christian Heath, Dirk Vom Lehn, Jonathan Osborne

\section{To cite this version:}

Christian Heath, Dirk Vom Lehn, Jonathan Osborne. Interaction and interactives: collaboration and participation with computer-based exhibits. Public Understanding of Science, 2005, 14 (1), pp.91-101. 10.1177/0963662505047343 . hal-00571050

\section{HAL Id: hal-00571050 \\ https://hal.science/hal-00571050}

Submitted on 1 Mar 2011

HAL is a multi-disciplinary open access archive for the deposit and dissemination of scientific research documents, whether they are published or not. The documents may come from teaching and research institutions in France or abroad, or from public or private research centers.
L'archive ouverte pluridisciplinaire HAL, est destinée au dépôt et à la diffusion de documents scientifiques de niveau recherche, publiés ou non, émanant des établissements d'enseignement et de recherche français ou étrangers, des laboratoires publics ou privés. 


\title{
Interaction and interactives: collaboration and participation with computer-based exhibits
}

\author{
Christian Heath, Dirk vom Lehn, and Jonathan Osborne
}

It is increasingly recognized that social interaction and collaboration are critical to our experience of museums and galleries. Curators, museum managers and designers are exploring ways of enhancing interaction and in particular using tools and technologies to create new forms of participation, with and around, exhibits. It is found, however, that these new tools and technologies, whilst enhancing "interactivity," can do so at the cost of social interaction and collaboration, inadvertently impoverishing co-participation, and cooperation. In this paper we address some of the issues and difficulties that arise in designing for "interactivity" and in particular point to the complex and highly contingent forms of social interaction which arise with, and around, exhibits. The paper is based on a series of video-based field studies of conduct and interaction in various museums and galleries in London and elsewhere including the Science Museum and Explore@ Bristol.

\section{Introduction}

In recent years, science centers and museums in the UK have received substantial funds from the government and other institutions to renew, replace and redevelop existing science exhibitions and to create new science centers. These exhibitions are being developed to kindle people's interest, and facilitate new forms of participation, in science, and often attempt to communicate science in novel ways to the public. They display a large number of computer-based exhibits. The managers and designers of the exhibitions presume that "interactives" can increase the time visitors spend with exhibits, facilitate social interaction and collaboration between visitors, and enhance the exhibition's ability to communicate science to the public.

A growing number of studies have begun to assess the effectiveness of computer-based exhibits in science exhibitions - which, in this paper, we refer to as "interactives." However, we still have little understanding of how the visitors examine and make sense of interactives. This paper draws on field observation and video-recording undertaken as part of a small research project funded by the Wellcome Trust. Data collection was carried out in a number of new science exhibitions in the UK, amongst them the Wellcome Wing (Science Museum, London), Explore-At-Bristol and Green's Mill (Nottingham). These exhibitions include a 
larger number of interactives that are designed to facilitate engagement and participation, and to communicate aspects of science. The paper explores the ways in which visitors participate with and interact around the exhibits. It is particularly concerned with the forms of social interaction that emerge at interactives.

\section{Background}

Before we briefly discuss our approach and some of our observations of people using interactives, it is perhaps worthwhile raising a few background issues.

Until recently, the effectiveness of exhibits was largely assessed by measurements developed in the behavioral sciences. These measurements highlight the importance of visitors" "dwell-time" at and their learning from exhibits (Screven, 1976; Shettel, 2001). With the cognitive turn in large parts of the social sciences in the 1970s and 1980s, visitor studies increasingly shifted their interest towards visitors' learning from exhibits. This shift in focus inspired a raft of studies that attempt to demonstrate that visitors do learn from exhibitions. They also provide information for managers and designers of exhibitions as to the development of more effective exhibitions. In particular, they led to propositions to change the layout of exhibitions and the design of exhibit features, labels and other information resources to increase the visitors' dwell-time in exhibitions and with exhibits (Falk, 1983, 1993; Serrell, 1993); such studies also include discussions about ways in which cognitive variables such as "interest," "motivation" or "attitude" could be influenced to improve visitors' experience of exhibitions (Csikszentmihalyi and Hermanson, 1995; Perry, 1993).

More recently, visitor studies have been influenced by a shift in the cognitive sciences towards an interest in the way in which social interaction and talk impact on people's learning and understanding (Lave and Wenger, 1991; Wenger, 1999; Wertsch, 1991). Likewise, within the field of science education, there has been an increasing emphasis on the role and significance of language in the learning of science (Lemke, 1990; Sutton, 1995; Wellington and Osborne, 2001). The importance of "social influences" for visitors' experience of exhibits had been noticed by behavioral researchers (Bitgood, 1993), sociolinguists and others (Blud, 1990; McManus, 1988, 1994). However, only the emergence of sociocultural theory occasioned a larger-scale turn in visitor studies towards studies of social interaction in museums. A growing body of research now reveals how objects, tools and artifacts feature in and mediate learning in visitor groups. These investigations increasingly argue that the museum experience is fundamentally influenced and shaped by social interaction and talk between visitors (Crowley, 2000; Leinhardt et al., 2002; Paris, 2002; vom Lehn et al., 2001).

Various studies in settings other than museums have shown that computers are extremely appealing to people, in particular children, and that they can facilitate social interaction (Scrimshaw and Wegerif, 1997). They have begun to stimulate debate about the suitability of computers for museums. Whilst computer-based exhibits lead to a relatively long dwell-time (Schulze, 2001; Serrell and Raphling, 1992; Wohlfromm, 2002), the screen and the interfaces (mice, keyboard, touch-screen) are often too small and clumsy to encourage social interaction (Flagg, 1994). Nevertheless, computer-based exhibits are increasingly viewed as a means to enhance the effectiveness of museums in communicating information to the public in different and novel ways and in facilitating new forms of participation and "interactivity." They are also seen as a way to support and engender social interaction and discussion amongst visitors (Bradburne, 2000; Thomas and Mintz, 1998). 


\section{Interaction and interactives}

This paper is based on a research project conducted in a number of science centers and museums, amongst them the Wellcome Wing at the Science Museum (London) and the science center Explore@Bristol. Both the Science Museum and Explore house cutting-edge interactive exhibits which have been highly commended for providing new forms of interactivity and participation. Nevertheless, despite the high acclaim in which the exhibitions are held, we have relatively little knowledge of the forms of interaction and participation that emerge with and around the computer-based exhibits.

As part of the project we gathered approximately 500 hours of video data and a substantial corpus of field observations. We have also had lengthy discussions with museum managers, designers and educationalists as well as with visitors themselves. The analysis of the data draws on recent developments in the social sciences, namely ethnomethodology (Garfinkel, 1967) and conversation analysis (Sacks, 1992). These approaches direct analytic attention to the ways in which participants, in situ, produce and coordinate their actions and activities in concert or collaboration with others. The practicalities of the approach have been discussed in various publications (Goodwin, 1981, 1994; Heath, 1986, 1997; Heath and Hindmarsh, 2002).

This paper draws on video-based field studies to consider the forms of conduct and social interaction which arise with, and around, a number of computer-based interactive exhibits in new science exhibitions. In discussing our observations we wish to address two underlying issues: first we wish to explore how we can design exhibits that facilitate interaction and collaboration amongst visitors, rather than simply between an artifact and an individual, and second, we discuss what methods are most appropriate to explore and evaluate conduct and collaboration with and around interactives.

\section{Prescribing interaction}

The computer-based exhibits that form the basis of many exhibits in the science exhibitions that have been subject to our research, largely involve technologies developed for the individual user - a small screen and a touch-screen interface. These systems require the individual to follow and respond to instructions displayed on the screen. Our interest lies with how the actions at the exhibit emerge when other people, companions and strangers, are in the same locale.

The first example was recorded at the Test Yourself Word Skills exhibit in the science center Explore@Bristol. The exhibit is designed to test the linguistic skills of visitors. It consists of a conventional 19-inch active screen monitor which is placed on a large floorstanding casing and visitors are provided with a seat directly in front. Interaction is through touching the screen. The system presents the visitor with a series of tests that become progressively more difficult as she or he proceeds through a series of successive topics and issues. At the end of the exercise the visitor is provided with a score. Completing the sequence of actions and achieving a score can take up to ten minutes; and in some cases the user repeatedly carries out the same test to improve her or his result.

The example begins after a man who has explored the Test Yourself Word Skills exhibit for some time gives way to his partner. She instantly engages with the game and progressively responds to the queries and puzzles posed by the system; queries and puzzles that are delivered in response to her previous answer. Throughout the "interaction" the woman remains visually and physically oriented towards the screen and uses her right hand 
to select responses and progress the activity. When a new screen opens up she asks the man, "What do you do here?"

The man neither provides his companion with an explanation of the test nor configures his position to the screen to collaborate with her, but reaches over her shoulder and interacts with the exhibit. Although she asks him to "stop that," he continues his participation and touches the screen again occasioning her to briefly slap his hand.

The example illustrates some of the problems in visitors' interaction at computer-based exhibits. The system entails one of the most pervasive and highly structured models of human-computer interaction. It initiates a series of sequences to enable a single user to achieve a particular goal. The "interaction" with the exhibit is primarily designed for a single user who undertakes a series of actions which are responses to pre-specified questions or puzzles posed by the computer system. The form of interaction therefore prescribed by the exhibit is designed to facilitate the involvement of a single user; indeed, the design of the exhibit minimizes the opportunities for others to participate and undermines the emergence of collaborative activities. It provides others who stand behind the user with only little opportunity for collaboration and interaction. In the case at hand, even when the woman encourages her companion to contribute to the task at the exhibit, the man does not engage in a collaborative activity but prompts the system to respond to his actions.

It is worthwhile raising an additional point. It is inevitable that others will arrive at the exhibit when a visitor has already begun the "game." If the queue is short, or they are with the visitor who has begun the game then it is likely they will be able to see at least a part of the action which arises on screen. In this, as in many cases, even before the visitor has his or her "turn," he or she will have been witness to some of the queries and puzzles posed by the exhibit and the answers selected by the previous user. When they begin their turn, therefore, users are to some extent already aware of the game, its questions and puzzles. It is unlikely that they experience the exhibit in the ways intended by the designers. In some sense they have already seen at least part of the process once, so it is far from being new or a surprise. Later moves in the game are often those which are familiar to the (next) user, a form of "second hand" use.

The Test Yourself Word Skills exhibit does appear to provide visitors with an interesting challenge that can engage individuals in an activity for a relatively lengthy period of time. It provides an extended and progressive form of interaction with the exhibit and visitors are given a way of assessing the range and depth of their vocabulary. It achieves these aims, though at the cost of precluding co-participation and collaboration; to a large extent those accompanying the principal user simply become witness to an event. The form and function of the exhibit, the interaction it affords, and the lack of visual and tangible access it provides to those even within a relatively close proximity, undermine the coparticipation and collaboration of others. In a sense therefore, a complex form of interaction with the exhibit is achieved at the cost of undermining interaction between people with and through the exhibit.

\section{Voicing instructions}

The characteristic forms of interaction we find with Test Yourself Word Skills are by no means unique and reflect aspects of interaction which arise with and around other computerbased exhibits that are designed using conventional computer hardware and interfaces. In the Wellcome Wing of the Science Museum in London there are a number of interactive exhibits which despite being housed in large amoeba-like casings, commonly know as "bloids," involve users in relatively lengthy sequences of conventional computer-based 
activity. They use mainly a touch-screen interface though one or two do provide alternative methods of interaction. One of those exhibits is known as the Sex Change Exhibit; it allows visitors to take a photograph of themselves and change various physical characteristics so that they appear to have changed sex or aged.

Consider the following example. We join the action as three adults attempt to use the exhibit. Soon after their arrival, the man stands back, realizing that he is unable to see the screen or its operation. Edith remains with her friend Jenny who adopts a position at the exhibit and tries to operate the touch-screen.

After a few actions on the screen, Jenny presses a button to take the photograph only to discover that she is not properly aligned to the camera which consequently fails to capture an image appropriate to be manipulated in the further course of actions. Jenny then sits down and begins the procedure once again. This time her friend Edith helps her by providing instructions as to how to align her face to the camera. As Jenny adjusts her position, Edith provides advice as to how she should align towards the camera and then recommends that her friend take the picture. Once again, Jenny fails to produce a realistic image and the two friends begin once more, attempting to produce an appropriate alignment to the camera. After successive attempts they abandon the exhibit and move to try something else in the exhibition.

As with Edith and Jenny, visitors' dwell-time at the Sex Change Exhibit is often quite lengthy, anything up to four or five minutes. Moreover, though the exhibit provides limited access to multiple participants to see what is happening, we do find two or three visitors gathering around the exhibit and engaging in discussion.

It therefore can be argued that the Sex Change Exhibit is relatively successful in two ways. It encourages collaboration between visitors and visitors' dwell-time at the exhibit is relatively lengthy. However, analysis of the video-recordings reveals that when people use the exhibit, we find that in many cases users spend a substantial proportion of their time attempting to make the exhibit work in the way intended by the designers. The character of the collaboration, the social interaction which arises at the exhibit, is often limited to one person helping the other to follow the instructions, the prescribed sequence of actions to use the exhibit. Visitors' dwell-time at the Sex Change Exhibit becomes extended not by virtue of participants discussing the content of the exhibit and its relationship to our perception of sex characteristics and identity, but rather in having to make successive attempts to produce a satisfactory image, an image which is clear enough to be able to see the user in the guise of the opposite sex. The collaboration therefore which arises is largely concerned with trying to operate the exhibit rather than discussing, or even appreciating, personal characteristics.

Test Yourself Word Skills and the Sex Change Exhibit are not unusual computer-based exhibits. They utilize basic information systems and conventional hardware. They embody many of the features of common, conventional, computer-based interactive exhibits found in science centers and museums. Like many other computer-based exhibits, they are designed for a principal user who interacts individually with the system to achieve a particular goal. The interaction with the system is scaffolded to elicit successive, single actions from the user in response to "moves" by the system, be they instructions, questions, queries or other methods. The organization of the interaction is a series of two-part sequences of action, computer-user, computer-user and so on, which is designed for the use of a single respondent. The conventional input and display technologies used in these exhibits also undermine the collaboration of others by restricting the ability of people gathered at the exhibit to see the screen, to see the principal user's operation of the system, and to select items or moves on the screen itself. Co-participation and collaboration is restricted in large 
part to watching the principal user "interacting" with the system and occasionally helping or interjecting comments.

\section{Interactives for collaboration}

There is a growing interest in developing exhibits that support interaction and collaboration amongst multiple participants. It is increasingly recognized that in developing these forms of interactive it is necessary to move away from conventional computing hardware and singleuser interfaces to exhibits which provide real-time access to a number of participants who may simultaneously engage in interdependent activities (Bradburne, 2000). Designing these multi-party interactives has proved problematic and it remains questionable whether many of the exhibits provide more than common access to a field of action that is created by one or two participants.

One of the more innovative examples is the interactive, circular tables found on the top floor of the Wellcome Wing at the Science Museum, in the exhibition called "In Future." Interactive games are projected onto three tables in the gallery. At seven locations around the table, small, round, turnable plates and an illuminated button are embedded into the tables. Participation in the games works by virtue of turning the plates and pressing the buttons. The games address controversial topics: chip implants in children that allow their parents to track them, male fertility, driverless cars. To encourage discussion and debate, at the end of each game a question is projected on to the table; visitors then vote "Yes" or "No" on this question. On arriving at the tables a button lights up to indicate whether the visitor has the authority to select the next game. The exhibit has been greeted with some commendation and has proved popular especially with children and teenagers.

As with other computer-based exhibits, dwell-time at the tables is lengthy, often more than five minutes, and people speak highly of the exhibit in surveys after the event. The seating arrangements placed around the tables possibly further extend the time visitors spend with the exhibits. Our own observations suggest that the tables are perhaps most successful when they involve two or three different participants who arrive at the same time. In these circumstances, individuals are able to produce a series of coordinated contributions and develop a coherent, mutually focused activity. However, problems do arise.

Most of the games do not encourage social interaction and collaboration between visitors. Neither the design of the interface to the game nor the organization of the games encourages visitors to collaborate on the completion of the game. Hence, the multi-party exhibit turns out to be a high-tech game board that allows multiple individuals to play their individual game. However, (brief) verbal exchanges and debates amongst companions and strangers do emerge after the completion of the game. The question that is projected on to the table occasions visitors to respond by pressing a button, "Yes" or "No." When the illuminated button indicates each other's answer to the question and the projection on the table shows the group's culminated response, the visitors voice their opinions about the responses and question the reasoning behind them. However, they rarely discuss the topic or content that the exhibit is trying to communicate through the game.

Some of the games require the participants to carefully follow the events on the table. Participants do not necessarily arrive at a table at the beginning of a game or they are briefly inattentive and therefore not aware of the sequence of events on the table. Hence, they are not able to detect whether responses that arise on the tables are a consequence of their own action or caused by moves of other participants. In other words, visitors lose track of how they are affecting the changing images on the table and of course how the actions of other participants are contributing to the game. In turn, it becomes increasingly problematic for 
participants to coordinate their actions with others and to develop a coherent, interdependent collaborative activity. We have noticed that, as visitors lose track of the activity as it appears on the table, their gestures and bodily activity becomes increasingly animated and dramatic. Through their bodily actions and vocalizations, they attempt to display to their coparticipants the actions they are producing and the associated "responses" revealed by the system. The interaction becomes increasingly "mediated" through the participants' bodies rather than through the principal focus and scene of action on the table.

Participation at the projection tables in the Science Museum illustrates the difficulty designers face in creating exhibits that engender collaboration involving more than one or two visitors. In particular, the tables reveal the difficulties in enabling visitors to coordinate distinct activities with each other when they have limited access to the operation of the exhibit and the contributions of others. It is not surprising therefore that many interactives that support collaboration either treat the visitors as a group and have them undertaking single actions in concert with each other, or implement a management structure which oversees and coordinates the different actions of the participants. Designing exhibits that support the highly variable and contingent forms of participation and collaboration that arise in museums and galleries is indeed difficult, and it is hardly surprising that it is by luck, rather than by design, that one or two exhibits turn out to be relatively successful. Whether any of them achieve their original goals is less certain.

\section{Rethinking interaction}

The recent design and deployment of novel, computer-based exhibits is grounded on the assumption that they enhance the visitors' museum experience by facilitating and supporting interaction and thus make a significant contribution to the formation of a public understanding of science. Educational and cognate research in visitor studies shows that learning and cognitive development can be supported when people become involved in lasting activities with objects and artifacts and engage in social interaction and discussion with another. From a socio-linguistic perspective, learning requires adopting the norms of the language of that discipline. For individuals, this requires their participation, through talk and writing, in thinking through and making sense of the scientific events, phenomena and their explanation. Active participation by learners is, therefore, key to providing an effective learning environment. For talking offers an opportunity for conjecture, argument and challenge. In talking, individuals will articulate reasons for supporting particular conceptual understandings and attempt to justify their views. Others will challenge, express doubts and present alternatives so that a clearer conceptual understanding will emerge. In such a manner, knowledge is co-constructed by the group. In particular, it is the group interaction that enables the emergence of an understanding whose whole is more than the sum of the individual contributions. The extent to which such an environment is, or is not, supported by exhibits is, therefore, one critical measure of their effectiveness.

Managers and designers of science centers and museums draw on such ideas when they make decisions about the development of computer-based exhibits that, they believe, support both lasting attention to a single task or activity and social interaction.

However, the model of interaction underlying the design of many of these exhibits is implicitly, sometimes explicitly, drawn from computer science or at least from the ways in which people are thought to interact with computer systems and not from sociocultural theory. It is a model that pervades the design of computing technology ranging from simple workstations through to complex systems. The model has a long-standing tradition in artificial intelligence and human-computer interaction (HCI) (Dreyfus, 1992/1972; 
Suchman, 1987). There is not the space here to discuss the approach in any detail but it is worthwhile mentioning one or two points. The model is characterized by its focus on the individual and the individual's interaction with the artifact or system. Its designers assume that activities derive from plans and goals, and that actions are organized in terms of rules that determine patterns or sequences of conduct to allow those goals to be achieved. The execution of action involves complex cognitive processing through which the individual develops representations of the system and enacts the appropriate sequence of conduct. Many computer-based systems are based implicitly on this approach to human interaction and ironically perhaps it was computer systems and their operation which provided the basis for the model in the first instance, not unlike the ways in which the telephone exchange became a model of the mind in the 1930s.

It seems the term "interactive" is misleading. It encompasses an extraordinary range of tools, technologies and techniques, objects and artifacts which are designed to create "interactivity" in museums and galleries. It includes sophisticated information systems which prescribe complex forms of interaction between the user and the exhibit through to "low-tech" artifacts designed to enhance visitors' understanding of particular objects. Different interactives engender very different forms of interaction and provide highly variable opportunities for co-participation and collaboration. As yet, we know little of the conduct and collaboration that different interactives afford, still less of the ways in which they might contribute to learning.

We believe that the observations from our research may have a bearing on the evaluation of current computer-based exhibits as well as on the design and development of new exhibitions. In designing and developing exhibits for science centers and museum we have to reshape the ways in which we think of and conceptualize the visitor, breaking free from individualistic models which continue to pervade "interactives" and the very idea of "interactivity." Unless we place the social and interactional at the heart of the agenda we will continue to be frustrated by the unanticipated ways in which people use our interactives and disappointed when we examine their conduct and experience, let alone their learning. The lone visitor wandering through galleries and achieving a pure aesthetic or scientific encounter with objects is largely a misconception despite the wishes of certain curators in more contemporary spaces. The presence and conduct of others profoundly influences what we see and what we do and the opportunities that arise for exploration, investigation and learning. Visitors encounter and use interactives in interaction with companions and strangers, and the design and layout of the interactives impact on the emergence of the forms of participation and interaction in the exhibition. Our discovery and experience of the museum arises in and through this social interaction and, if they are to meet with success, our interactives have to be sensitive to, and designed with respect for, the social interaction which will inevitably inform their use.

It seems that the use of conventional evaluation methods to assess the effectiveness of computer-based exhibits does not resonate with the activities that arise at these relatively new exhibits. Computer-based exhibits prescribe the sequential organization of visitors' actions and encourage the user to spend time interacting with the system. At the same time, the design of these exhibits affords curious forms of co-participation; whilst a small number of visitors use the exhibits, the majority of visitors become an audience to the events and experience the exhibit "second hand." Quantitative indicators such as attracting power and dwell-time do not capture the quality of the visitors' experience. They provide neither any insight into how the user follows the prescribed sequence of actions, nor any understanding of the various forms of participation through which the audience experiences the exhibit. 
Video-based field studies may be a way forward to deal with these shortcomings of conventional methods to evaluate computer-based exhibits.

One final point: despite the substantial body of research concerned with visitor behavior and the growing interest in interactivity in science centers and museums, we still know relatively little as to how people respond to exhibits in science centers and museums and interact with and around the objects and artifacts they contain. Save for a few important exceptions (Ash, 2002; Callanan et al., 2002; Crowley, 2000; Crowley et al., 2001), conduct and social interaction at the exhibit-face remains unexplored territory and yet it provides the foundation, the very basis, to people's experience of and the public understanding of science in science centers and museums. It seems critical therefore that in developing new forms of exhibit and exhibition which are designed to enhance the public understanding of science through interaction, we need a more thorough and detailed understanding of how visitors organize their conduct and interaction in science centers and museums, and of the ways in which their actions and activities arise in and through social interaction with others. Without this understanding, it is unlikely that the hopes, principles and ideas which underlie the development of new forms of interactivity will be reflected in the actual response and conduct of visitors.

For an illustrated version of the papaer see: http://www.kcl.ac.uk/depstra/pse/mancen/ witrg/

\section{Acknowledgements}

We would like to thank James Bradburne, Richard Glassborow, Ben Gammon, Malcolm Baker and others for helping stimulate and facilitate the program of research of which this paper is part. We would also like to thank Paul Luff, Jon Hindmarsh, Marcus SanchezSvensson, Jo Graham, Kathy Sykes, Sarah Stellard, Dinah Casson, Sarah Hyde, and others for their ideas and insightful comments concerning the issues discussed in this paper. The project on which this paper is based is "Communicating Science in Museums and Galleries" and is funded by the Wellcome Trust (no. 059833).

\section{References}

Ash, D. (2002) "Negotiation of Biological Conversations in Informal Learning Settings," in G. Leinhardt, K. Crowley and K. Knutson (eds) Learning Conversations: Explanation and Identity in Museums, pp. 371-400. Mahwah, NJ: Laurence Erlbaum Associates.

Bitgood, S. (1993) "Social Influences on the Visitor Museum Experience," Visitor Behavior 8(3): 4-5.

Blud, L.M. (1990) "Social Interaction and Learning Among Family Groups Visiting a Museum," Museum Management and Curatorship 9(1): 43-51.

Bradburne, J.M. (2000) Interaction in Museums. Observing Supporting Learning. Hamburg: Libri Books on Demand.

Callanan, M.A., Jipson, J.L. and Stampf Soennichsen, M. (2002) "Maps, Globes, and Videos: Parent-Child Conversations about Representational Objects," in S. Paris (ed.) Perspectives on Object-Centered Learning in Museums, pp. 261-83. Mahwah, NJ: Laurence Erlbaum Associates.

Crowley, K. (2000) Building Islands of Expertise in Everyday Family Activity: Musings on Family Learning in and Out of Museums. Pittsburgh, PA: Museum Learning Collaborative.

Crowley, K., Callanan, M.A., Tenenbaum, H.R. and Allen, E. (2001) "Parents Explain More Often to Boys than to Girls during Shared Scientific Thinking," Psychological Science 12(3): 258-61.

Csikszentmihalyi, M. and Hermanson, K. (1995) "Intrinsic Motivation in Museums: What Makes Visitors Want to Learn?," Museum News 74(3): 34-7 and 59-62.

Dreyfus, H.L. (1992/1972) What Computers Still Can't Do: A Critique of Artificial Reason. Cambridge, MA: The MIT Press.

Falk, J. (1983) "Time and Behavior as Predictors of Learning," Science Education 67: 267-76.

Falk, J.H. (1993) "Assessing the Impact of Exhibit Arrangement on Visitor Behavior and Learning," Curator 36(2): $133-46$. 
Flagg, B.N. (1994) "Visitors in Front of the Small Screen. What Research Says about Learning in Science Museums," ASTC News 2: 21-4.

Garfinkel, H. (1967) Studies in Ethnomethodology. Oxford: Blackwell.

Goodwin, C. (1981) Conversational Organization: Interaction Between Speakers and Hearers. New York: Academic Press.

Goodwin, C. (1994) "Recording Human Interaction in Natural Settings," Pragmatics 3: 181-209.

Heath, C. (1986) Body Movement and Medical Interaction. Cambridge: Cambridge University Press.

Heath, C. (1997) "The Analysis of Activities in Face to Face Interaction Using Video," in D. Silverman (ed.) Qualitative Research: Theory, Method and Practice, pp. 183-200. London: SAGE.

Heath, C. and Hindmarsh, J. (2002) "Analysing Interaction: Video, Ethnography and Situated Conduct," in T. May (ed.) Qualitative Research in Action, pp. 99-121. London: SAGE.

Lave, J. and Wenger, E. (1991) Situated Learning. Legitimate Peripheral Participation. Cambridge: Cambridge University Press.

Leinhardt, G., Crowley, K. and Knutson, K. (eds) (2002) Learning Conversations in Museums. Mahwah, NJ: Laurence Erlbaum Associates.

Lemke, J.L. (1990) Talking Science: Language, Learning, and Values. Norwood, NJ: Ablex.

McManus, P. (1994) "Families in Museums," in R. Miles and L. Zavala (eds) Towards the Museum of the Future: New European Perspectives, pp. 81-97. London: Routledge.

McManus, P.M. (1988) "Good Companions: More on the Social Determination of Learning-related Behavior in a Science Museum,” Journal of Museum Management and Curatorship 7(1): 37-44.

Paris, S. (ed.) (2002) Perspectives on Object-Centered Learning in Museums. Mahwah, NJ: Laurence Erlbaum Associates.

Perry, D.L. (1993) "Beyond Cognition and Affect: The Anatomy of a Museum Exhibit," in D. Thompson, S. Bitgood, A. Benefeld, H. Shettel and R. Williams (eds) Visitor Studies: Theory, Research and Practice, Vol. 6, pp. 43-7. Jacksonville, AL: Center for Social Design.

Sacks, H. (1992) Lectures on Conversation. Oxford: Blackwell.

Schulze, C. (2001) Multimedia in Museen. Standpunkte und Aspekte interaktiver digitaler Systeme im Ausstellungsbereich. Wiesbaden: Deutscher Universitäts Verlag.

Screven, C.G. (1976) "Exhibit Evaluation: A Goal-Referenced Approach,” Curator 52(9): 271-90.

Scrimshaw, P. and Wegerif, R. (eds) (1997) Computers and Talk in the Primary Classroom. Clevedon: Multilingual Matters.

Serrell, B. (1993) "Using Behaviour to Define the Effectiveness of Exhibitions," in S. Bicknell (ed.) Museum Visitor Studies in the 90s, pp.140-4. London: Science Museum.

Serrell, B. and Raphling, B. (1992) "Computers on the Exhibit Floor," Curator 35(3): 181-9.

Shettel, H. (2001) "Do We Know How to Define Exhibit Effectiveness?," Curator 44(4): 327-34.

Suchman, L. (1987) Plans and Situated Actions. The Problem of Human-Machine Communication. Cambridge: Cambridge University Press.

Sutton, C. (1995) "The Scientific Model as a Form of Speech," in G. Welford, J. Osborne and P. Scott (eds) Research in Science Education in Europe, pp. 143-52. London: Falmer Press.

Thomas, S. and Mintz, A. (eds) (1998) The Virtual and the Real: Media in the Museum. Washington, DC: American Association of Museums.

vom Lehn, D., Heath, C. and Hindmarsh, J. (2001) "Exhibiting Interaction: Conduct and Collaboration in Museums and Galleries," Symbolic Interaction 24(2): 189-216.

Wellington, J. and Osborne, J. (2001) Language and Literacy In Science Education. Buckingham: Open University Press.

Wenger, E. (1999) Communities of Practice: Learning, Meaning, and Identity. Cambridge: Cambridge University Press.

Wertsch, J. (1991) Voices of the Mind. London: Harvester Wheatsheaf.

Wohlfromm, A. (2002) Museum als Medium. Neue Medien in Museen. Köln: Herbert von Halem Verlag. 


\section{Authors}

Christian Heath is Professor, King's College London and leads the Work, Interaction and Technology research group. With members of the group, he is currently undertaking a number of projects concerned with conduct and social interaction in museums and galleries, as well as studies of work and technology in areas including medicine, transport, the news media, and auctions. His publications include Technology in Action, with P. Luff (Cambridge University Press, 2000).

Dirk vom Lehn is a Research Fellow at King's College London and currently works on a project funded by the Economic and Social Research Council (ESRC) "Science in Society" programme. He is undertaking various studies including research on social interaction in museums and galleries and the development and deployment of novel exhibits and exhibitions.

Jonathan Osborne is Professor of Science Education at King's College London. He was an ESRC fellow for their "Public Understanding of Science" programme and is a member of the ESRC "Science and Society" panel. Currently he is the Principal Investigator at King's for the NSF funded "Centre for Informal Learning and Schools" (CILS) (NSF Award No. 0119787).

Correspondence: Christian Heath, Work, Interaction and Technology Research Group, The Management Centre, King's College, Franklin-Wilkins Building, London SE1 9NN, UK; e-mail: christian.heath@kcl.ac.uk 